\title{
Halofantrine Hydrochloride (Halfan) Induced Toxicity of the Pancreas in Wistar Rats
}

\author{
${ }^{1 *}$ DIDIA, B C; ${ }^{2}$ DEDE, E B; ${ }^{2}$ OBIANIME, A O \\ ${ }^{1 *}$ Department of Anatomy and ${ }^{2}$ Pharmacology, Faculty of Basic Medical Sciences \\ College of Health sciences, University of Port Harcourt \\ PMB 5323, Port Harcourt, Nigeria
}

\begin{abstract}
The toxicity of halofantrine hydrochloride to the pancreas of wistar rats (Rattus norvegicus) was studied using twenty five male wistar rats divided into five groups of five rats per group. Group A (control group) was given only clean water. Groups B. C. D and E received $0.7 ; 1.4 ; 2.1$ and $2.8 \mathrm{~g} / \mathrm{kg}$ Body not of halofantrine hydrochloride administered orally every six hours for three times (complete dose) respectively. The results showed Odema and swelling of pancreatic acini cells and obliteration of interstitial spaces. This toxicity effect was found to be dose dependent and significantly different from the normal integrity of the cells observed in the control experiment: The result underscored a possible toxic effect halofantrine when administered into man. Based on the result obtained, there was need for caution on the use of halfan in the treatment of malaria, particularly in cases of drug abuse. It is suggested that further studies are required to elucidate the implication of this toxicity to both the endocrine and exocrine functions of the pancreas. @JASEM
\end{abstract}

Halfan is one of the effective anti-malarial drugs in clinical use to date. It provides a fast and effective treatment for all forms of malaria particularly that caused by the multidrug resistant strain of plasmodium falciparum. Halfan is a phenanthromethanol whose anti-malarial activity was first recognized during World War.2. (Wiselogle,1946). Furthermore, in the 1960's the Walter Reed Army Institute of Research in Washington, prompted by the increasing apparent failure of current measures in the field, came out with two compounds, which when tested in humans proved effective against strains of plasmodium falciparum which were resistant to chloroquine. One of these drugs was mefloquine which became commercialized in 1982 while the other drug was Halfan. Halfan is blood schizonticide which exerts its action on the erythrocytic stage of the life cycle (trophozoite and schizont) of the malarial parasite. Data from Peters et al (1987) suggests that halfan has effect on the mitochondria and heamatozoin vesicles of he malaria parasite. They concluded that this indicated a similarity in action to quinine. Various studies have described the deleterious effect of commonly prescribed anti-malarials on cellular morphology of the reproductive organ in experimental animals. Halfan has been shown to induce the formation of immature spermmatocytes and increase cellularity in the testes (Didia et $\underline{\text { al }}$; 2002, Igbigbi; 1992). Metakalfin has been shown to cause $60 \%$ reduction in oestrus day level of serum Luteinizing hormone ( $\mathrm{LH}$ ) and so could possibly inhibit ovulation and therefore has contraceptive potential (Didia et al ; 2000). Chloroquine has been reported to interrupt the oestrus cycle (Okanlawon and Ashiru; 1992), impair sperm motility (Okanlewon et al; 1992). The contraceptive potential of chloroqiune had also been highlighted by Noronha et al (1991). Chloroqiune has also been shown to have teratogenic effect on Ieydig cells of mature Wistar rats (Akpa and Sigh, 1992). Morris and Valantich (1993) have shown that certain Drugs incuding nitrosomethylurea are capable of inducing focal acini cell hyperplasia (FACH) in rat's pancreas. Dib et al (1993) showed that ethanol altered pancreatic blood flow (PCBF) and caused swelling of acini cells, while ethanol given with furosemide caused sparse focal necrosis without acini swelling. It is in that light that we investigated the effect of halfan on the histology of the pancreas.

In this paper we report the toxicity of halfan to the pancreas of mature Wistar rats. (Rattus norvegicus)

\section{MATERIALS AND METHODS}

Twenty five male wistar rats (Rattus norvegicus) obtained from the animal house of University of Port Harcourt were used for the current study. The rats were tham put in cages and fed with growers mash enriched with Calcium Supplement and clean tap water ad libitum. Two weeks were allowed for acclimatization at the end of which the rats were weighed and randomly separated into five groups (A, $\mathrm{B}, \mathrm{C}, \mathrm{D}$ and E) consisting of five rats per group Group A---Served as control, fed with normal rat feed and clean water Group B--Each animal received $0.1 \mathrm{~g} / \mathrm{Kg}$ body wt. halfan 6 hourly x 3 doses. Group C. Each animal received $1.4 \mathrm{~g} / \mathrm{kg}$ body wt halfan 6 hourly x 3 doses. Group D---Each animal received $2.1 \mathrm{~g} / \mathrm{kg}$ body wt halfan 6hourly x 3 doses. Group E--Each animal received $2.8 \mathrm{~g} / \mathrm{kg}$ wt halfan 6 hourly $\mathrm{x} 3$ doses. 
The drugs were administered orally by means of syringes: the animal were sacrificed $48 \mathrm{hrs}$ after drug administration and the pancreas dissected out, fixed in $100 \%$ formal saline. The tissue were sliced and dehydrated with different increasing concentrations $(50,70,80,95$ and $100 \%)$ of ethanol for about $24 \mathrm{hrs}$ the tissues were then cleared with xylene to remove the alcohol and improve their refractive index, they were then imbedded in the molten paraffin wax allowed to solidify in the wax. The resultant blocks were sectioned with a shandon on AS 325 Rotary Microtone Slides were later obtained after sectioning.

The slides were stained with heamatoxylin/eosin solution and the stained pancreas slides were examined for histopathological lesions due to halofantrine hydrochloride toxicity, using a binocular Olympus light microscope.

\section{RESULTS AND DISCUSSION}

The results obtained from the current study were considered based on the following: The physical and behavioural changes in the animals, the gross anatomical changes in the pancreas and the pathological features in the pancreas all due to exposure to halofantrine hydrochloride. Considering the physical and behavioural changes, no significant weight changes were observed in the animals when the control and test groups were compared. However, loss in agility and appetite were noticed in the test group when compared with the control animals. Furthermore, on the gross anatomical changes, the gross morphology of both the control and test groups remained unchanged with the distinct parts (head, neck, body and tail) being observed. However, fat deposits were noticed in the surface of the pancreas of test group animals.

Considering the histopathological features, light microscopic examination; of the control (fig.1) and group B (fig.2) revealed normal glandular tissue of the pancreas consisting of branched acini cells surrounded and completely lobulated by loose connective' tissue'. Wide interlobular and interstitial spaces existed between the acini cells. Group C micrograph (fig. 3) indicated the existence of two types of glandular tissue in intimate association. The main mass was the exocrine acini cells in which was embedded the endocrine acini cells of the of islet of langerhan. There was moderate swelling and oedema of acini cells with consequent moderately diminshed interstitial spaces (fig. 3). Furthermore, in groups D and E (figs.4and 5) there were marked swelling interstitial space more pronounced in group E fig.5) than in group D (fig.4). Based on results obtained in the current study, administration of halofantrine into the rats did not show any noticeable physical nor behavioural changes in the animals despite loss in agility observed in the test animals. Report by Tracy and Webster (2001) has shown that antimalarial agents such as quinine increases the tension response to a maximal stimulus delivered to muscle directly or through nerves, also increase the refractory period to muscle so that the response to tetanic stimulation is decreased. The excitability of the motor end-plate region decreases. Therefore response to nerve repetitive, stimulation to acetylcholine is reduced. It is possible that the same mechanism may be responsible for the reduced agility observed in the rats administered with high dose $(2.1-2.8 \mathrm{~g} / \mathrm{kg}$ halofantrine hydrochoride ) in the current study.

Furthermore, the results indicated changes in histopatholological features in fig.4 and 5. Marked swelling of rats administered with 2.1 and $2.8 \mathrm{~g} / \mathrm{kg}$ halofantrine hydrochloride respectively. This consequenlty resulted in diminished interstitial spaces, an effect that was dose dependent. This result seemed to corroborate, with the report (Dib, et al; 1993), in which the acute effects of ethanol and ethanol plus furosemide on pancreatic capillary blood flow in rats were investigated. The histopathological features in that study shoved acini cells with significant decrease in pancreatic capillary blood flow in the group of animals which received ethanol only. It was thus concluded in that study that the depressant effect of ethanol in pancreatic capillary blood flow was responsible for the swollen pancreatic acini cells; an effect furosemide antagonized. The oedema in the pancreatic acini in figs 4 and 5 may be due to occlusion of the pancreatic capillary blood flow or as a direct inflammatory action of halofantrine in the pancreatic tissues.

Based on the foregoing, caution is therefore needed in the administration of antimalarials i.e. halofantrine based on the possible adverse effects of the drugs at high doses.

\section{REFERENCES}

Akpa, O. A; Singh S. P (1989). Teratogenic effect of chloroquine on leydig cells of mature wistar rats. In: Book of abstracts of papers presented at $1^{\text {st }}$ National conference of Anatomical Society of Nigeria, Kano, Nigeria: 21-26.

Dib, J. A; Cooper-Vastola S. A; Meirelles, R. (1993). Acute effects of ethanol and ethanol plus furosemide on pancreatic capillary blood flow in rats. Am. J. Surgery; 166(1): 18-23.

Didia, B; C; Igbigbi P. S; Dapper D. V (2002). Preliminary study on the effect of Halofantrine 
Hydrochloride on the Testes of mature wistar rats. J. Appl. Sci Environ. Mgt; 6 (1): 45-48.

Didia, B. C; Igbigbi, P. S. and Fawehinmi H. B. (2000). The effect of Metakefin on ovulation and oestrous cyclic in rats. W. Afr. J. Pharmacol. Drug Res; 16(1\&2): 14-18.

Hallwood, P. N; Horton R. J. O; Sullivan, K. M. Parr; S. N. (1989). Halofantrine and Pruritis. Lancet; 11: 397-398.

Igbigbi, P.S. (1992). Effects of Halofantrine Hydrochloride on Testicular morphology , histology and histochemistry. M. Sc Thesis submitted to the University of Calabar, Calabar, Nigeria.

Monis, B; Valentich, M. A. (1993). Promoting effects of Mancozeb on pancreas of nitrosomethylurea treated rats. Programa centro de Biologia Cellular Y Desarrelo (CEBYD-CONICET), Cordiba,

Argentina. Carcinogenesis; 14(5): 929-933.

Noronha, C. C; Okanlawon, A. O; Ashiru, O. A. (1991). Chloroquine: An aprocah to the development of a female contraceptive in developing countries West Afr. J. of Anatomy; 1(12): 66 .
Okanlawon A. O; Noronha, C. A; Ashiru O. A. (1990). Effect of chloroquine on peripheral level of testosterone, gonadotrophin and sperm motility. West Afri. J. Pharmacol. Drug Res.; 9:31-33.

Peters, W; Obinson, L; Ellis, D. S (1987). The chemotherapy of rodent malaria XL11; Halofantrine and Halofantrine resistance. Ann. Trop. Med. Parasitol.; 81 (5): 639-646.

Sowunmi, A; Walker, O; Salako, L A (1989). Pruritis and antimalaria drugs in Africans. Lancet; $11: 213$.

Sullivan, G E; Takags, E (1971). Comparative teratogenicity of pyrimethamine in rats and Hamsters. Teratology; 4:205-209.

Tracy, J. W; Webster, L. T: (2001) Drugs used in the Chemotherapy of potozoan infection- Malana: In Goodman and Gilman's The Pharmacological Basis of Therapeutics Tenth edn. Pp 1087.

Wiselogle, F Y (1946). A Survey of antimalarial drugs 1941-1945. J. W. Edwards Ann Arbor; $1: 309-324$ 